\title{
Incentive-Compatibility in a Two-Stage Stochastic Electricity Market with High Wind
} Power Penetration

Exizidis, Lazaros; Kazempour, Jalal; Papakonstantinou, Athanasios; Pinson, Pierre; De Greve, Zacharie; Vallee, Francois

Published in:

IEEE Transactions on Power Systems

Link to article, DOI:

10.1109/TPWRS.2019.2901249

Publication date:

2019

Document Version

Peer reviewed version

Link back to DTU Orbit

Citation (APA):

Exizidis, L., Kazempour, J., Papakonstantinou, A., Pinson, P., De Greve, Z., \& Vallee, F. (2019). Incentive-

Compatibility in a Two-Stage Stochastic Electricity Market with High Wind Power Penetration. IEEE Transactions on Power Systems, 34(4), 2846 - 2858. https://doi.org/10.1109/TPWRS.2019.2901249

\section{General rights}

Copyright and moral rights for the publications made accessible in the public portal are retained by the authors and/or other copyright owners and it is a condition of accessing publications that users recognise and abide by the legal requirements associated with these rights.

- Users may download and print one copy of any publication from the public portal for the purpose of private study or research.

- You may not further distribute the material or use it for any profit-making activity or commercial gain

- You may freely distribute the URL identifying the publication in the public portal 


\title{
Incentive-Compatibility in a Two-Stage Stochastic Electricity Market with High Wind Power Penetration
}

\author{
Lazaros Exizidis, Member, IEEE, Jalal Kazempour, Senior Member, IEEE, \\ Athanasios Papakonstantinou, Member, IEEE, Pierre Pinson, Senior Member, IEEE, Zacharie De Grève, \\ Member, IEEE, and François Vallée, Member, IEEE
}

\begin{abstract}
A major restructuring of electricity markets takes place worldwide, pursuing maximum economic efficiency. In most modern electricity markets, including the widely adapted Locational Marginal Price (LMP) market, efficiency is only guaranteed under the assumption of perfect competition. Moreover, market design is heavily focused on deterministic conventional generation. Electricity markets, though, are vulnerable to strategic behaviors and challenged by the increased penetration of renewable energy generation. In this paper, we cope with the aforementioned bottlenecks by investigating the application of Vickrey-Clarke-Groves (VCG) auction in a twostage stochastic electricity market. The VCG mechanism achieves incentive-compatibility by rewarding market participants for their contribution towards market efficiency, being attractive from both market operation and participants perspectives. Both traditional and VCG market-clearing approaches are explored and compared, investigating as well the impact of increasing wind power penetration. The main shortcoming of VCG, i.e., not ensuring revenue-adequacy, is quantified in terms of market budget imbalance for various levels of wind power penetration. To this end, a novel ex-post budget redistribution scheme is proposed, which achieves to partially recover budget deficit.
\end{abstract}

Index Terms-electricity market, incentive-compatibility, stochastic market-clearing, Vickrey-Clarke-Groves, budget imbalance redistribution

\section{INTRODUCTION}

\section{A. Background and Motivation}

Under perfect competition ${ }^{1}$ in Locational Marginal Price (LMP) markets, energy price is turned into a parameter that cannot be controlled by any of the market agents. Perfect competition, though, is subject to the assumption that all market agents are truthful with respect to their marginal costs or utilities. However, market agents are in general rational and aim at maximizing their profit from market participation. Thus, they may offer to the market at prices different than their true

L. Exizidis, Z. De Grève and F. Vallée are with the Department of Power Electrical Engineering, University of Mons, Mons, 7000 Belgium (e-mail: exlazaros@gmail.com; zacharie.degreve@umons.ac.be; francois.vallee@umons.ac.be).

J. Kazempour and P. Pinson are with the Department of Electrical Engineering, Technical University of Denmark, Kgs. Lyngby, 2800 Denmark (e-mail: seykaz@elektro.dtu.dk; ppin@elektro.dtu.dk).

A. Papakonstantinou is with the Department of Management Engineering, Technical University of Denmark, Kgs. Lyngby, 2800 Denmark (e-mail: athpapa@dtu.dk).

${ }^{1}$ Perfect competition refers to the condition where the participating agents cannot exercise market power in order to influence the clearing outcomes of the market [1]. In terms of electricity markets, under perfect competition, market agents reveal their true preferences, e.g. their actual marginal costs/utilities. marginal costs to affect market prices for their own benefit, i.e., increasing their profit. Such strategic behaviors may jeopardize market efficiency by changing the economic dispatch and decreasing social welfare. There are several empirical papers that assess the existence of "market power" in real-world electricity markets, e.g., [2]-[8]. Motivated by the limitation of LMP markets to ensure truthful market participation, we explore in this paper an incentive-compatible mechanism that has the ability to induce truthful information from market participants. More specifically, we apply the Vickrey-ClarkeGroves (VCG) auction [9]-[11] on a two-stage stochastic electricity market [12], [13]. The VCG payment scheme imposes truthful participation as dominant strategy to market agents (both producers and consumers) without, however, enforcing them to publicly reveal any private information.

An additional limitation of the current electricity market design globally, is the fact that it is heavily focused on conventional deterministic generation. However, modern electricity markets are challenged by the accelerated penetration of variable wind power generation. Thus, we use in this paper a two-stage stochastic electricity market setup to properly take into account the wind power uncertainty at the dayahead stage. This implies that the dispatch decisions in the day-ahead stage are made, while considering the recourse actions in the real-time for each plausible wind power scenario. This scheme is expected to better accommodate wind power uncertainty, leading to an increased market efficiency (i.e., lower system cost in expectation), assuming that a realistic range and probability distribution of scenarios are considered [12], [13]. The benefits and shortcomings of the stochastic market design are discussed in [14] and [15].

Using the aforementioned two-stage stochastic setup, we evaluate the VCG mechanism against the LMP mechanism, under both perfect and imperfect competition. In particular, we aim at exploring the applicability of a market mechanism that would set the two objectives at once: ensuring perfect competition in the market through an incentive-compatible mechanism, while facilitating the integration of massive renewable sources with stochastic generation.

The way the LMP- and the VCG-based mechanisms clear the market is identical. They both solve an optimization problem whose objective function is to maximize the market's social welfare, constrained by market agents' offers, grid constraints and nodal power balance equalities. However, these two mechanisms are differentiated in the way they calculate 
producers' payments and consumers' charges. In the LMPbased mechanism, the market operator pays producers based on their production quantity times the market price. Thus, those producers have an incentive to possibly affect market prices to their own benefit by strategic offering. However, in the VCG-based market mechanism, participants' payments are defined as the economic difference in social welfare resulted by their participation in the auction. For example, the payment of the market operator to a producer corresponds to a profit equal to the difference between the value of market's social welfare when that producer participates in the market and the value of social welfare when that producer is out of the market. Therefore, the producer's profit is indeed the economic value that the producer brings to the market. From this producer's perspective, who aims at maximizing its profit, the value of social welfare without its participation in the market is a parameter (not a variable), and therefore the producer is not able to affect market's outcomes without participating in it. Hence, producer's objective falls into maximizing the value of the social welfare when participating in the market, to earn the highest possible profit. Interestingly, the highest social welfare is obtained when the producers offer at their true marginal costs. This is the reason why the VCG mechanism guarantees incentive-compatibility, i.e., it eliminates the market power of market participants, either producers or consumers, by endogenizing social welfare into their optimization objective.

In traditional LMP markets, payments to producers and charges of the demands are calculated based on the unique equilibrium price, resulting in a budget-balanced market, i.e., demand charges are equal to generation payments ${ }^{2}$. Therefore, revenue-adequacy in the market is guaranteed, since the market's revenue from demand payments is sufficient to cover generation costs. Note that this is the case if non-convexities, e.g., binary variables representing the on/off commitment status of conventional generators, are ignored. However, payments under the VCG mechanism are not calculated based on a unique price. Instead, for each of the scheduled producers and consumers, payments are calculated independently of the other participants' payments. Therefore, VCG does not, by design, guarantee budget-balance, since consumers' valuation of electricity may not be equal to the suppliers' payments. The inability of VCG mechanism to guarantee strict budget balance, i.e., payments of consumers being equal to payments to the producers, has been mathematically proven in [16]. More specifically, under the context of a double-sided market as the one we study in this paper, this may lead to budget imbalance towards both directions, i.e., positive or negative [17], [18].

Table I summarizes the main properties of the VCG mechanism, comparing them with the corresponding ones of the LMP markets under both competitive and strategic setups. The LMP market achieves maximum efficiency, cost-recovery and revenue-adequacy only under the assumption that com-

\footnotetext{
${ }^{2}$ This budget-balance condition still holds in the LMP markets with congested transmission network, since the resulted surplus corresponds to the so-called congestion rent, which is eventually paid to the transmission owner or to the financial transmission right holders.
}

petition in the market is perfect ${ }^{3}$. Although regulators may impose regulatory policies to mitigate market power (e.g., by imposing price offer caps), these interventions do not guarantee achieving a perfect competition. By design, the LMP mechanism leads to a perfect competition only if the number of market participants grows to infinity, under which the LMP market outcomes converge to the VCG outcomes [19]. On the other hand, the application of a VCG auction to an electricity market ensures maximum efficiency, costrecovery and incentive-compatibility as dominant strategies. It may, however, result in budget deficit for the market operator which should be exogenously recovered based on an additional payment scheme (similar to uplift mechanisms in the US markets [20]). In this work, we quantify the corresponding budget imbalance (positive or negative) under a network-constrained market structure and propose an ex-post mechanism to partially ${ }^{4}$ recover revenue-adequacy. The latter redistributes budget imbalance, by proportionally charging (rewarding) agents for their contribution towards negative (positive) budget imbalance. The proposed mechanism, motivated by relevant economic literature for singlesided markets [22], aims at reducing budget imbalance while making it practically difficult for agents to violate incentivecompatibility and market efficiency ${ }^{5}$. It should be noted that since these four desirable properties cannot be met at the same time by a single market mechanism [21], it is up to the priorities of market regulators and policy makers to decide which properties are the most important to keep, at the cost of relaxing another property.

For the purpose of this assessment we apply and compare VCG and LMP mechanisms in two different test cases. Firstly, a 24-bus test system is used which is large enough to allow a thorough comparison of the two mechanisms, while at the same time it makes feasible the calculation of the market equilibrium under imperfect competition. Then, in order to explore the practical implementation of the VCG mechanism a second test case is presented based on a 118-bus test system. In the latter case, the LMP market-clearing under imperfect competition is ignored since the case study focuses on the scalability of the LMP versus the VCG mechanism, which is not related to the competitiveness of the market.

\section{B. Literature Review and Contributions}

Considering the relatively recent restructuring of electricity markets, mechanism design theory and its application to electricity markets is not yet widely explored in the technical literature. In this section we offer a review of the most relevant research literature, followed by the corresponding contributions of the present paper.

\footnotetext{
${ }^{3}$ In a stochastic market setup, these market properties are ensured in expectation, but not necessarily for each individual scenario [12]. It is possible to guarantee cost-recovery and revenue-adequacy by scenario, but at the cost of losing some desirable market properties, such as market efficiency [14].

${ }^{4}$ No market design satisfies at the same time efficiency, cost-recovery, incentive-compatibility and revenue-adequacy [21].

${ }^{5}$ The redistribution payment is independent of the agents' decisions, while it is practically hard for them to form a strategy that can impact the budget deficit, which is the basis of the proposed redistribution mechanism.
} 
TABLE I

Properties of LMP AND VCG MARKET MEChanisMS

\begin{tabular}{llll} 
& $\begin{array}{l}\text { Competitive } \\
\text { LMP }\end{array}$ & $\begin{array}{l}\text { Strategic } \\
\text { LMP }\end{array}$ & VCG \\
\hline Market Efficiency $^{1}$ (in exp.) & $\checkmark$ & $x$ & $\checkmark$ \\
Cost-Recovery $^{2}$ (in exp.) $_{\text {Revenue-Adequacy }}$ (in exp.) $^{4}$ & $\checkmark$ & $\checkmark$ & $\checkmark$ \\
Incentive-Compatibility $^{4}$ & $\checkmark$ & $\checkmark$ & $x$ \\
\hline
\end{tabular}

${ }^{\star}$ Competitive $L M P$ is an ideal model, used as benchmark.

${ }^{1}$ Market efficiency is maximized when market outcomes align with the maximum social welfare.

${ }^{2}$ Cost-recovery implies that producers' profit is non-negative.

${ }^{3}$ Revenue-adequacy implies that market operator receives enough revenue to recover the expenses of market operation, i.e., no budget deficit in the market. ${ }^{4} \mathrm{~A}$ mechanism is called incentive-compatible if every participant can maximize its objective just by acting according to its true preferences.

In [23], authors propose a market design that achieves efficiency despite missing information, ensuring incentivecompatibility and cost-recovery. Producers' payments are divided into two parts, one being the cost compensation and the other one being an information payment, specifically designed to elicit truthful marginal costs from producers. However, the study does not ensure that payments to producers are minimized, due to the nature of the dual payment scheme. Authors in [17] investigate VCG auction for supply and demand bidding in an energy market with conventional producers. The advantages and shortcomings of VCG are then explored without, however, considering the impact of wind power uncertainty which is dominant in modern electricity markets. Furthermore, [17] highlights that the mechanism will lead to budget deficit, which could potentially be recovered by additional payments from consumers.

In a more recent study, [24] introduces an incentivecompatible pool-based market design based on a Bayesian approach to cope with some of the aforementioned shortcomings. In this study, authors consider prior common knowledge of the individual costs probability distribution, without accounting for wind power uncertainty. Finally, recent research paper [18] applies VCG mechanism to wholesale electricity markets considering wind uncertainty. The results are then compared to a (ideally) perfectly competitive LMP market, considering reserve allocation in day-ahead (DA) to anticipate real-time (RT) imbalances. In contrast to the present paper, the aforementioned study does not anticipate RT market operation through a two-stage market-clearing approach. Besides, it does not consider an imperfect competition among strategic producers in the LMP-based market mechanism and, while it quantifies the budget deficit, it does not explore any mechanism to recover revenue-adequacy of the market operator.

Even though applicability of VCG to electricity markets has been studied before in the aforementioned papers, to the best of the authors' knowledge, adapting a VCG mechanism in a two-stage stochastic electricity market, additionally considering a budget imbalance redistribution scheme, forms a novel contribution to existing power systems literature. To this end, the contribution of this paper is summarized below:

- a VCG auction is applied to a two-stage stochastic market and comprehensively compared against the LMP market under both perfect and imperfect competition,

- potential budget imbalance under the VCG mechanism is quantified for two case studies and a novel mechanism for partially recovering revenue-adequacy in the market is proposed,

- and, finally, the impact of wind power penetration on the market outcomes, and more specifically on budget imbalance, is evaluated for increasing levels of wind power penetration.

\section{Paper Organization}

The remainder of the paper is organized as follows: Section II describes the main features along with the considered market-clearing mechanisms, and proposes a new mechanism for partially redistributing budget imbalance. Section III presents a case study considering multiple conventional and wind power producers that compete in a network-constrained market. Scalability issues of the VCG market mechanism are explored in Section IV based on a 118-bus test case. Finally, Section V concludes the paper and discusses future perspectives.

\section{FORMULATION}

\section{A. Features and Assumptions}

Throughout this work, two market-clearing mechanisms are explored, i.e., the VCG market mechanism and the LMP market mechanism, considering a stochastic two-stage electricity market. Three different models are, then, constructed in order to allow for a thorough comparison of the two mechanisms. The three market models are described below:

1) Model "Competitive LMP", refers to a perfectly competitive electricity market, cleared based on the LMP mechanism. In the corresponding model, participants are considered to be price-takers and submit their true cost/utility to the market operator, who clears a stochastic two-stage market accordingly [12], [13]. This is an ideal model, which is used as a benchmark.

2) Model "Strategic LMP", corresponds to an LMP market where strategic producers are present. Under this context, an iterative diagonalization approach is followed [25], in order to identify the equilibrium of the market with respect to producers' strategic offers. Then, market operator clears the market based on producers' offers and demands' bids at the equilibrium.

3) Model " $V C G$ ", consists of a mechanism based on the VCG auction theory, i.e., each producer and each consumer is paid/charged proportionally to the impact it has on social welfare.

Under the scope of this study, a number of necessary assumptions are made. An energy-only market is considered which is modeled as a stochastic two-stage DA market, in order to better capture the uncertainty of wind power generation [13]. All models are solved enforcing transmission network constraints, using a lossless DC power flow approach [12]. Inter-temporal constraints, e.g., ramping limits of conventional units, are not enforced and thus a single-hour auction is considered. The operational cost of wind power producers is considered to be 
zero. In Strategic LMP model, producers behave strategically with respect to their price offers of conventional generation, but not regarding power quantities and wind power generation. Finally, demand is considered to be elastic to price as well as deterministic to exclude additional sources of uncertainty.

\section{B. Market-Clearing Under the LMP Mechanism}

A market with increased wind power penetration is investigated. Thus, to achieve better DA schedules, a two-stage stochastic market-clearing approach is followed, which clears DA market anticipating potential RT adjustments [12], [13].

The LMP market-clearing mechanism ensures maximum efficiency, under the assumption that market participants are price-takers, i.e., do not exercise market power. This leads to a well-defined model, where the market is cleared based on true generation costs and demand utilities. The objective function of the two-stage stochastic market-clearing represents the maximization of expected social welfare, i.e., $\mathbb{E}[S W]$, which consists of DA and expected (based on a wind power forecast) RT social welfare, expressed by (1) below:

$$
\operatorname{Max}_{\boldsymbol{x}, \boldsymbol{y}_{\boldsymbol{\omega}}}\{\overbrace{\sum_{d \in D} U_{d}(\boldsymbol{x})-\underset{\omega}{\mathbb{E}}\left[\sum_{i \in I} C_{i}\left(\boldsymbol{x}, \boldsymbol{y}_{\boldsymbol{\omega}}\right)+\sum_{d \in D} V_{d}\left(\boldsymbol{y}_{\boldsymbol{\omega}}\right)\right]}^{\underset{\omega}{\mathbb{E}}[S W]}\}
$$

subject to

$$
\begin{aligned}
& h\left(\boldsymbol{x}, \boldsymbol{y}_{\boldsymbol{\omega}}\right)=0 \\
& g\left(\boldsymbol{x}, \boldsymbol{y}_{\boldsymbol{\omega}}\right) \leq 0
\end{aligned}
$$

where $D$ is the set of demands, $I$ is the set of conventional producers, $\omega$ is an index for scenarios, $\boldsymbol{x}$ is the vector of scenario-independent (here-and-now) DA variables and $\boldsymbol{y}_{\boldsymbol{\omega}}$ is the vector of scenario-dependent (wait-and-see) RT variables. Furthermore, $U_{d}(\boldsymbol{x})$ is the utility of demand $d, C_{i}\left(\boldsymbol{x}, \boldsymbol{y}_{\boldsymbol{\omega}}\right)$ is generation cost of producer $i$ and $V_{d}\left(\boldsymbol{y}_{\boldsymbol{\omega}}\right)$ is the shedding cost of demand $d$. In constraints (1b)-(1c), $h($.$) and g($.$) are$ functions of the decision vectors $\boldsymbol{x}, \boldsymbol{y}_{\boldsymbol{\omega}}$ and define a number of equality and inequality constraints. The detailed formulation of (1) is available in [26].

In case of a perfectly competitive DA market, terms $U_{d}(\boldsymbol{x})$ and $C_{i}\left(\boldsymbol{x}, \boldsymbol{y}_{\boldsymbol{\omega}}\right)$ in (1) correspond to the actual values of demand utilities and generation costs, forming the "Competitive $L M P$ " model. In practice, the assumption of a perfectly competitive market does not usually hold and electricity markets are challenged by the presence of strategic producers [27], which may offer at prices different than their actual production costs. Thus, an increasing number of research efforts has been focusing on investigating market power in electricity markets under various setups, e.g., [28]-[31].

To account for strategic behaviors in the market, we additionally investigate a market with multiple strategic conventional producers. For each power producer, a bilevel optimization model is constructed, the upper-level of which maximizes producer's expected profit and the lower-level maximizes expected social welfare based on the same market mechanism as in (1). The formulation of such a bilevel problem for strategic producer $i$ is briefly given by (2):
$\left\{\operatorname{Max}_{\alpha_{i}}\left\{\underset{\omega}{\mathbb{E}}\left[\Pi_{i}\right]=\Pi_{i}^{\mathrm{DA}}\left(\alpha_{i}, \boldsymbol{x}\right)+\underset{\omega}{\mathbb{E}}\left[\Pi_{i}^{\mathrm{RT}}\left(\alpha_{i}, \boldsymbol{x}, \boldsymbol{y}_{\boldsymbol{\omega}}\right)\right]\right\}\right.$

subject to:

Optimization problem (1a) - (1c)

\},$\forall i \in \mathcal{I}$.

where objective function (2a) consists of the summation of DA and expected RT profits, i.e, $\Pi_{i}^{\mathrm{DA}}\left(\alpha_{i}, \boldsymbol{x}\right)$ and $\mathbb{E}\left[\Pi_{i}^{\mathrm{RT}}\left(\alpha_{i}, \boldsymbol{x}, \boldsymbol{y}_{\boldsymbol{\omega}}\right)\right]$, respectively. Furthermore, $\alpha_{i}$ is a variable corresponding to the price offer for conventional unit $i$, which is not necessarily equal to its marginal cost. Thus, $C_{i}\left(\boldsymbol{x}, \boldsymbol{y}_{\boldsymbol{\omega}}\right)$ is replaced in (2b) by $\alpha_{i}$.

The solution of the aforementioned bilevel model identifies the strategic price offers for each producer. Then, an iterative diagonalization approach is followed, to identify the equilibrium of the game among all producers [25], [31]. A more detailed presentation of "Strategic LMP" model is available in [26].

\section{Market-Clearing Under the VCG Mechanism}

The first step of applying VCG in the electricity market is to ensure efficient economic dispatch by using model (1), which maximizes social welfare given a perfectly competitive market. Note that VCG ensures a perfectly competitive market, through a payment scheme which aligns the objectives of individual participants with the maximization of social welfare.

Both Competitive LMP and VCG models yield the same DA and RT dispatch but different market-clearing prices. The LMPs in the former model are obtained as dual variables of power balance conditions, which are unique for all players within a transmission node. However, the market prices for any two agents in VCG mechanism might be different, despite being located at the same node.

The principle of payments under the VCG mechanism is fundamentally different than the one in the conventional LMPbased markets today. This mechanism pays each producer based on the economic value that it brings to the market, identified by the difference of the market's social welfare with and without that producer. This definition differentiates the value of production of two producers, even though they are located at the same node. For example, assume one producer is flexible, while the other one at the same node is inflexible. In an energy-only setup in which the producers are only paid based on their energy production (no capacity committed for reserve), although both producers generate the same good, the absence of the former may cause load shedding or wind spillage under some scenarios, showing the economic value of its flexibility to the market. Therefore, under the VCG scheme, the flexible producer may deserve to be rewarded more than the inflexible one. Another example would be considering two producers that have comparable marginal costs but considerably different scheduled power. In that case, the absence of the producer with the higher scheduled power is more probable to create the need for scheduling more expensive generation in the market compared to the smaller producer. Thus, its absence from the market will have a greater 
impact on social welfare than the smaller producer and, thus, it will be paid proportionally higher. The payment mechanism under VCG auction is explained below.

Let producer $i$ be the one whose revenue is to be calculated. The VCG payment scheme is designed to endogenize the social welfare function into producer $i$ 's profit-maximizing function. The latter is achieved by paying the producer the difference between: (i) the expected social welfare when all agents participate in the market increased by producer $i$ 's reported operational cost, and (ii) the expected social welfare when producer $i$ does not participate in the market. The expected social welfare when $i$ does not participate in the market, denoted by $\underset{\omega}{\mathbb{E}}\left[S W_{-i}\right]$, is derived by the solution of (1), excluding producer $i$ from the auction. Thus, the expected payment to producer $i$ (expected revenue of that producer), i.e., $\underset{\omega}{\mathbb{E}}\left[R V_{i}\right]$, is calculated by (3) below:

$$
\underset{\omega}{\mathbb{E}}\left[R V_{i}\right]=\overbrace{\left[\underset{\omega}{\mathbb{E}}[S W]+\underset{\omega}{\mathbb{E}}\left[C_{i}\left(\boldsymbol{x}, \boldsymbol{y}_{\boldsymbol{\omega}}\right)\right]\right]}^{\gamma}-\underset{\omega}{\mathbb{E}}\left[S W_{-i}\right]
$$

where $\underset{\omega}{\mathbb{E}}[S W]$ is the expected social welfare of all agents including $i, \underset{\omega}{\mathbb{E}}\left[S W_{-i}\right]$ is the expected market social welfare when producer $i$ is excluded from the auction at the optimal point, and $\mathbb{E}\left[C_{i}\left(\boldsymbol{x}, \boldsymbol{y}_{\boldsymbol{\omega}}\right)\right]$ is the reported operational cost of producer $i \stackrel{\omega}{\text { for }}$ its expected generation. Note that, the term indicated by $\gamma$ is the expected social welfare considering the contribution of all agents except $i$ (i.e., the term $-\underset{\omega}{\mathbb{E}}\left[C_{i}\left(\boldsymbol{x}, \boldsymbol{y}_{\boldsymbol{\omega}}\right)\right]$ is included in $\underset{\omega}{\mathbb{E}}[S W])$. To calculate $\mathbb{E}\left[S W_{-i}\right]$, we solve the market-clearing problem in (1), while agent $i$ is excluded from the market. The value of the objective function at the optimal point is equal to $\mathbb{E}\left[S W_{-i}\right]$.

Similarly, we define the expected revenue of each wind producer. Note that the operational cost of wind generation is considered zero for all wind producers.

Lastly, the expected payment received by consumer $d$ is given by (4) below:

$$
\underset{\omega}{\mathbb{E}}\left[R V_{d}\right]=\underset{\omega}{\mathbb{E}}\left[S W_{-d}\right]-\left[\underset{\omega}{\mathbb{E}}[S W]-U_{d}(\boldsymbol{x})\right]
$$

where $\underset{\omega}{\mathbb{E}}\left[S W_{-d}\right]$ is the expected market social welfare when consumer $d$ is excluded from the auction, $\underset{\omega}{\mathbb{E}}[S W]$ is the expected social welfare of all agents including $d$ and $U_{d}(\boldsymbol{x})$ is the cost consumer $d$ is willing to pay for its consumption.

Under this payment scheme, it can be proved that agents' dominant strategy is to report their true preferences, i.e., true generation cost and demand utility, leading to maximum social welfare (see [26] for the proof). Furthermore, producers' expected profit can be obtained by subtracting from (3) their corresponding generation costs, which under truthful submission of costs becomes equal to (5):

$$
\underset{\omega}{\mathbb{E}}\left[\Pi_{i}\right]=\underset{\omega}{\mathbb{E}}[S W]-\underset{\omega}{\mathbb{E}}\left[S W_{-i}\right]
$$

Based on (5), producers' expected profits are always nonnegative, ensuring cost-recovery in the market. The proofs regarding incentive-compatibility and cost-recovery for the VCG market mechanism can be found in [26].

\section{Budget Imbalance Redistribution Under the VCG Mecha- nism}

In this subsection, we explore a novel redistribution approach, which aims at ex-post recovering budget imbalance. Budget imbalance is the result of aggregate consumers' charges not being equal to the producers payments, thus leading the market operator with either an economic deficit (producer's payments are higher than consumers' charges) or with an economic surplus (producers' payments are lower than consumers' charges). The proposed mechanism charges agents that are responsible for the negative budget imbalance and rewards the ones that contribute towards revenue-adequacy. Motivated by the relevant economics literature for single-sided markets [22], we explore a redistribution mechanism adapted to a double-sided electricity market. The proposed redistribution scheme is able to distinguish each agent's positive (negative) contribution towards revenue-adequacy and rewards (charges) them with a corresponding additional payment.

Qualitatively, the proposed budget imbalance redistribution scheme is described by the flowchart in Fig. 1. The first step is to solve the original VCG market-clearing problem and calculate the value of budget imbalance $\left(S_{0}\right)$, i.e., the difference between aggregate payments received from demands and aggregate revenues of producers. In order to propose a fair mechanism for charging this additional payment to market participants, we first investigate the contribution of each market agent on the budget imbalance. Thus, we solve the market-clearing problem excluding each time market agent $n$, calculating the corresponding budget imbalance. The new budget imbalance is then denoted by $S_{-n}$. Note that agent $n$ can be either a consumer or a producer. If the resulted budget imbalance is positive, i.e., $S_{-n}>0$, and the initial budget imbalance is negative, i.e., $S_{0}<0$, then agent $n$ 's participation in the market contributes towards negative budget imbalance and it should be charged. On the other hand, in cases that initial budget imbalance is positive, i.e., $S_{0}>0$, then if excluding agent $n$ leads to lower budget imbalance, agent $n$ contributes towards positive budget imbalance and should be rewarded accordingly.

Note that the proposed redistribution scheme indicates the impact that each agent solely has on budget imbalance. If, according to the mechanism, an agent is not identified to affect budget imbalance, then its profit is not affected by the redistribution mechanism. For example, in a case with negative budget imbalance, if excluding agent $n$ from the market still leads to negative budget imbalance, then agent $n$ is neither charged nor rewarded. In that sense, if agent $n$ 's sole participation causes a budget deficit (identified by exploring the budget imbalance without agent $n$ 's participation), then no other agent is either charged or rewarded. Thus, we can distinguish which agent's participation jeopardizes revenueadequacy and which helps towards it. The next step is to define the exact redistribution payment of each agent. This additional payment (positive or negative) corresponds to agent's individual contribution on revenue-adequacy, in order to redistribute 


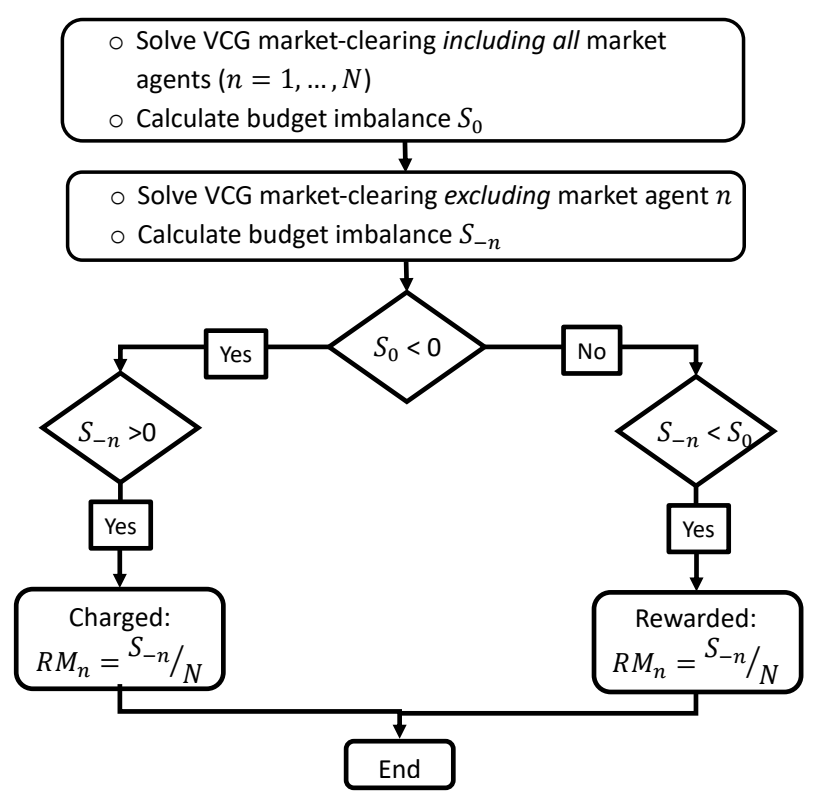

Figure 1. The proposed budget imbalance redistribution mechanism for the VCG market

budget imbalance proportionally. To this end, the additional payment derived by the redistribution mechanism for a market with negative budget imbalance is calculated as the surplus associated with each agent $n$ 's absence in the market, divided by the number of participating agents $N$. Note that agent $n$ 's redistribution payment, i.e., $\mathrm{RM}_{n}$, is constrained to be less than or equal to agent $n$ 's profit/utility, in order to maintain costrecovery. Cost-recovery of each agent is imposed under the ex-post redistribution mechanism as an explicit observation on the payment calculation. More specifically, we calculate each agent's redistribution payment and then check whether its total profit (i.e., profit in the market plus the profit/cost from the redistribution stage) is positive or negative. If the latter is positive, then we keep the redistribution payment as it is. However, in case the total profit is negative, then the redistribution payment is adjusted to be equal to the profit of the agent from the market, leading to a zero total profit for the agent. Similarly, in a market with positive budget imbalance, i.e., revenue-adequacy is satisfied, each agent that helps towards increasing positive budget imbalance is rewarded by the surplus associated with its absence in the market divided by the number of participating agents. The proposed approach has the following features/benefits:

1) It redistributes budget imbalance of the market in a proportional way, rewarding agents that contribute towards revenue-adequacy and charging agents that have negative impact on it.

2) It does not affect VCG market efficiency, since DA schedules and RT adjustments are exactly the same as in a perfectly competitive market.

3) It discourages strategic behaviors aiming to maintain VCG incentive-compatibility; redistribution payment $\mathrm{RM}_{n}$ is independent of agent $n$ 's decisions, being the budget imbalance when agent $n$ does not participate in the market.

4) It ensures ex-post cost-recovery by constraining the redistribution payment to be less than or equal to the corresponding agent's profit.

Note that, as mentioned before, no mechanism is capable of achieving individual rationality, efficiency and budget balance at the same time for general valuation functions [21]. Thus, the proposed redistribution approach cannot always guarantee full recovery of the negative budget imbalance, i.e., it might just reduce it.

\section{CASE STUdY: IEEE 24-BUS TEST System}

\section{A. Data}

A case study based on the IEEE 24-bus reliability test system [32] is considered, modified in order to better accommodate wind farms [33]. The considered total load is 2,207 MW, consisting of 17 demands (namely, D1-D17) with properties as listed in [33], while demand bids are elastic and the value of lost load is $€ 200 / M W h$. From the generation side, 12 conventional power units (namely, G1-G12) are considered, with total installed capacity of 3,375 MW. Each conventional unit offers at a quantity identical to its installed capacity and at a given price. In addition to conventional units, we consider 6 wind power units located in different buses, as proposed in [33]. Wind power scenarios are sampled from a beta distribution, as in [34], with shape parameters $(\alpha, \beta)=(5,1)$. An initial number of 2,000 wind power scenarios are generated and then reduced to 3 using $\mathrm{K}$-means clustering [35] to decrease computational cost, which is challenging for Strategic $L M P$ model. Lastly, multiple cases are evaluated for increasing wind power penetration, i.e., expected wind power generation divided by total load, ranging from $17 \%$ to $50 \%$.

\section{B. Market-Clearing Outcomes Under VCG and LMP Mecha- nisms}

The results for expected social welfare versus increasing levels of wind power penetration are presented in Fig. 2. Incentive-compatible VCG (before redistribution) as well as LMP under perfect competition lead to the same social welfare, due to the truthful submission of costs from the generation side. Note that truthfulness is an assumption for the LMP model but a dominant strategy for the VCG. The corresponding curve under imperfect competition in the LMP market is, as expected, lower for all wind penetration levels. Naturally, social welfare increases with wind power penetration for all three market models.

Due to space limitation, agent-specific results are presented only for agents with particular interest. Thus, Fig. 3 compares the profits for selected conventional producers across the three market models. The competitive LMP model is used as a benchmark for comparison, thus it is plotted as a line against the bar plot of the VCG and LMP strategic models. It is observed that producers' expected profit under $V C G$ model is equal to (e.g., producer G10) or greater than (e.g., producers G2 and G8) that in Competitive LMP. Additionally, there are cases where a producer has zero profit under LMP mechanism (being the marginal producer), but its profit under 


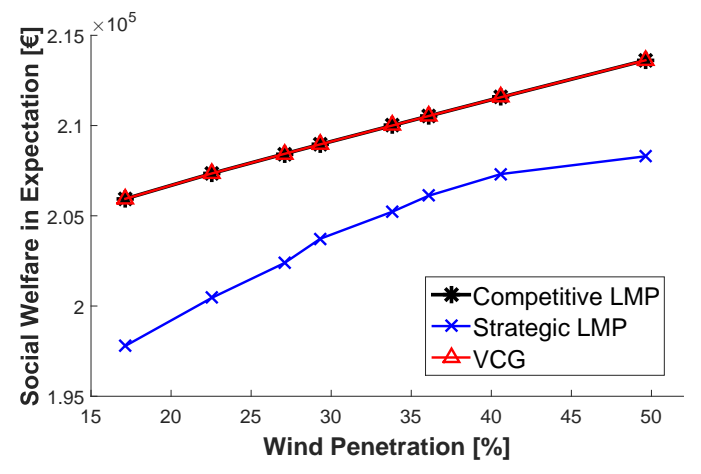

Figure 2. Expected market social welfare versus increasing levels of wind power penetration. Expected social welfare in both Competitive LMP and VCG models is the same since they end up in identical dispatch results; the only difference is the pricing scheme used.

$V C G$ mechanism is positive, e.g., producer G8. This indicates the main difference in the two payment mechanisms; $V C G$ payments depend on the contribution of each generator in social welfare maximization and not on a unique price that is set by the marginal producer. It is additionally observed from Fig. 3 that strategic offering could still be more beneficial for some producers, e.g., G8 and G10.

Regarding wind power producers, $V C G$ can be more beneficial compared to Competitive LMP. This can be observed by Fig. 4, and the comparatively equal or higher profits under VCG model, compared to Competitive LMP. However, it is also observed that Strategic LMP may lead to the highest profit. Wind producers, despite being competitive in the market, still get benefited by the strategic behavior of conventional producers under Strategic LMP model.

Similar to all other agents in the market, the location of wind power units might have an impact on the outcomes of the VCG mechanism. The absence of a wind power unit with a zero marginal cost will definitely decrease the market's social welfare. However, depending on the location of wind power unit, this absence may either intensify or diminish the congestion. In the former case (more severe congestion), the economic value of wind power unit, and thus the payment of market operator to this unit, will even increase. However, in the latter case, the wind power unit will have a comparatively lower economic value, leading to a lower payment to this unit.

Lastly, payments received from selected demands are presented in Fig. 5. It is observed that demands are expected to make lower payments under $V C G$ mechanism, reflecting their positive impact on social welfare. Thus, $V C G$ mechanism is more beneficial for consumers as well, compared to the LMP model under both strategic and competitive setups. Demands' payments do not change considerably with increasing penetration of wind power for each model, due to their relatively high offer prices.

Market budget imbalance is presented in Fig. 6 versus increasing levels of wind power penetration. Budget imbalance is defined as the difference between aggregate payments received from demands and aggregate payments made to producers. Note that, the LMP market model is revenue-adequate in expectation only, i.e., the budget imbalance is always non-
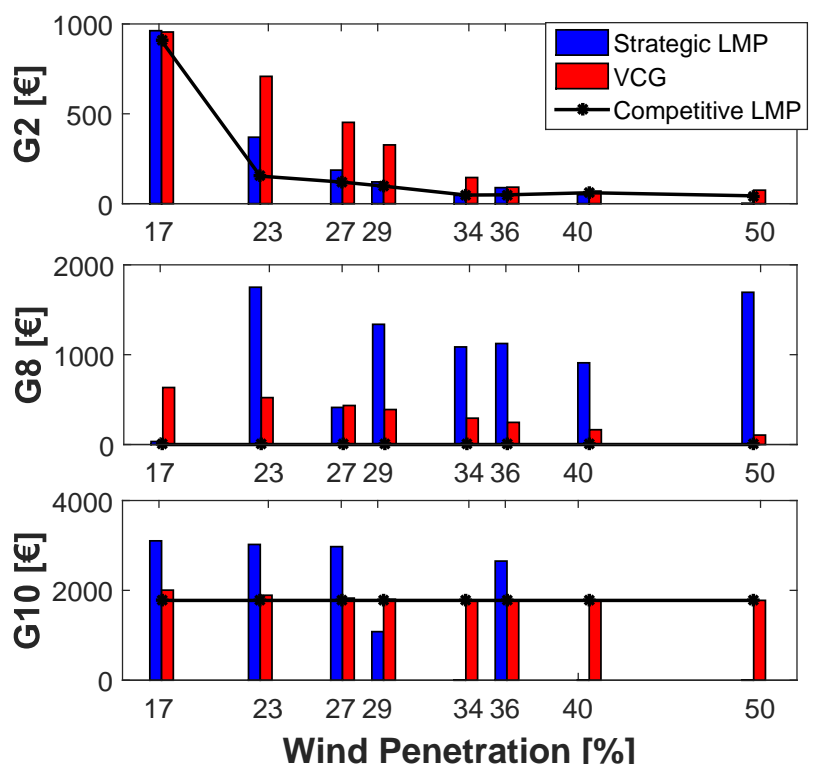

Figure 3. Expected profit of selected conventional producers versus increasing levels of wind power penetration
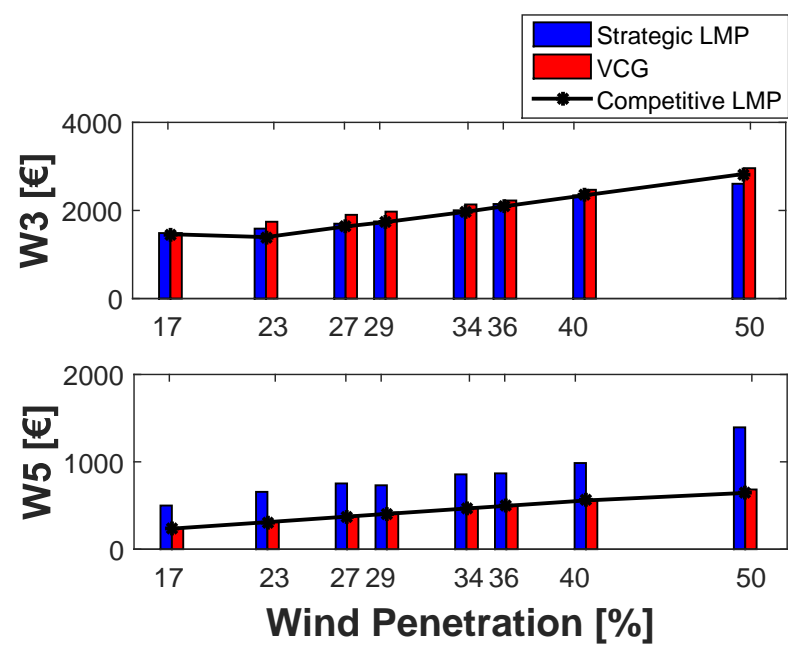

Figure 4. Expected profit of selected wind producers versus increasing levels of wind power penetration

negative in expectation, but it might not be per scenario [12]. In this case study it is observed that, considering a congested network, LMP model results in positive budget imbalance (both black and blue lines), which decreases with increasing penetration of wind power. A positive budget imbalance in the LMP mechanism is attributed to the so-called congestion rent payments in the congested network.

On the other hand, $V C G$ pricing is not nodal but individually derived per participant and, thus, market budget imbalance is not related explicitly to congestion rent. In Fig. 6 it is observed that market budget imbalance under $V C G$ is negative for low wind power penetration. This is explained by the comparatively lower payments received from demands compared to payments made to producers, both wind and conventional. This outcome changes for scenarios with higher 

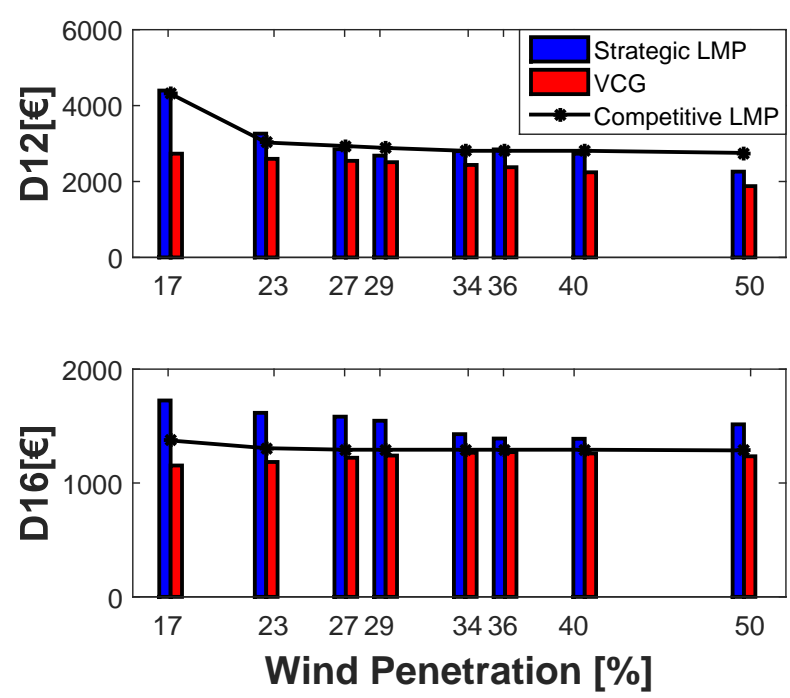

Figure 5. Expected payment of selected demands versus increasing levels of wind power penetration

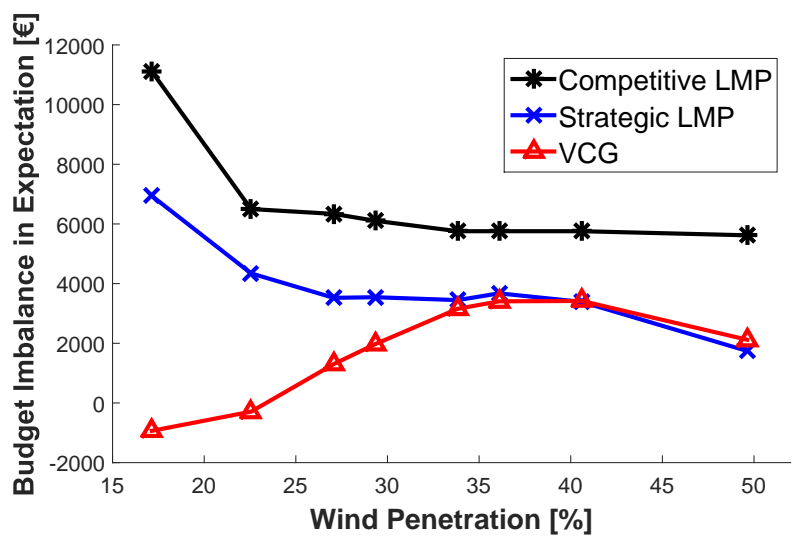

Figure 6. Budget imbalance of the market in expectation. Revenue-adequacy refers to the case of having non-negative budget imbalance.

than $23 \%$ wind penetration, where demand payments remain at the same levels but payments to conventional producers decrease resulting in positive budget imbalance. Following the increasing wind penetration, payments to wind producers also increase and, thereafter, market budget imbalance decreases accordingly, though remaining positive.

Prices in LMP markets can be different per node due to congestion in the network. Recall that energy prices in the stochastic LMP models anticipate probable network bottlenecks in RT operation and, thus, DA and RT prices are strongly coupled. On the other hand, VCG prices are defined by a different payment scheme and depend on the contribution of each generator in social welfare maximization, thus not forming a unique price which is set by the marginal producer. To clarify this with an example, let us consider producers G11 and G12, which are located at the same node. For wind penetration levels equal to $17 \%$, producer G11's payment corresponds to a market price of $€ 13.56 / \mathrm{MWh}$. On the other hand, producer G12, located at the same node with G11, receives a DA payment which corresponds to a market price of $€ 13.69 / \mathrm{MWh}$. The price difference, even relatively small, is

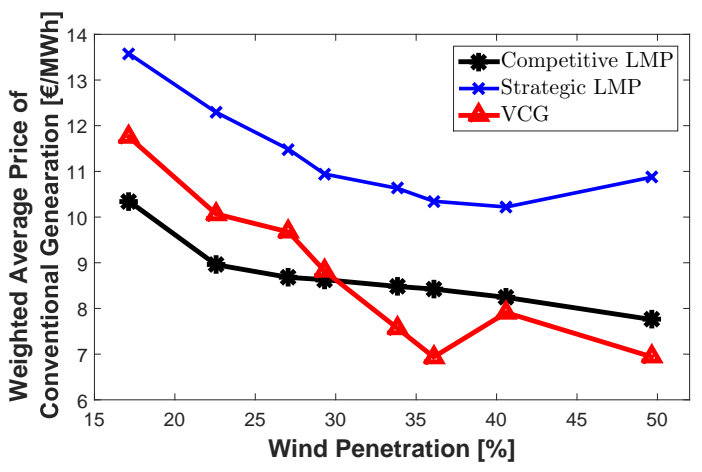

Figure 7. Conventional generation weighted average market prices versus increasing levels of wind power penetration

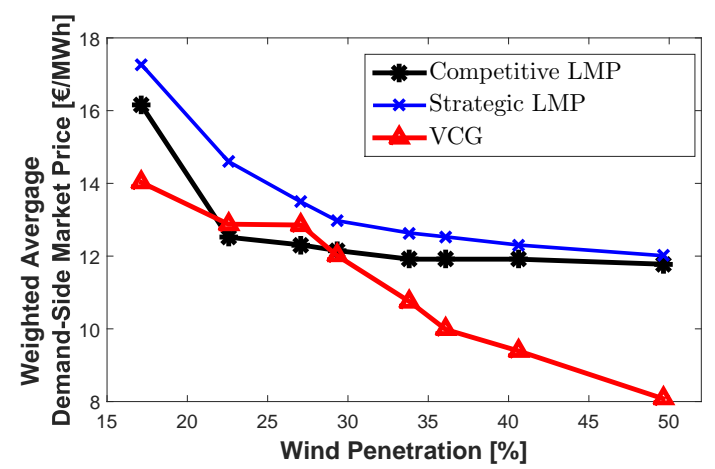

Figure 8. Demands' weighted average market prices versus increasing levels of wind power penetration

explained by the fact that the two producers have comparable marginal costs but different capacities. Thus, an absence of G12 from the market would require the scheduling of a larger amount of more expensive generation compared to the absence of G11, causing a comparatively greater impact on social welfare. Concluding, despite that producers G11 and G12 are connected to the same node of the system, there is no unique nodal price that defines their payment under the VCG.

For illustration reasons, weighted average prices for aggregate conventional generation and aggregate demands are presented in Figs. 7 and 8, respectively. Weighted average prices are the summation of all individual prices multiplied by the ratio of individual and total traded power in DA. It is observed that weighted average conventional generation prices are higher for $V C G$ mechanism for low wind power penetration and then become lower than the corresponding prices for Competitive LMP. Lastly, results for the demand-side prices show that for high levels of wind power penetration, $V C G$ demand-side prices decrease considerably. Note that, up to $27 \%$ of wind power penetration the weighted average prices of conventional generation under $V C G$ decrease, while the corresponding demand-side prices remain relatively unchanged. This explains the increasing trend of budget imbalance for low levels of wind power penetration, which accordingly becomes positive. 


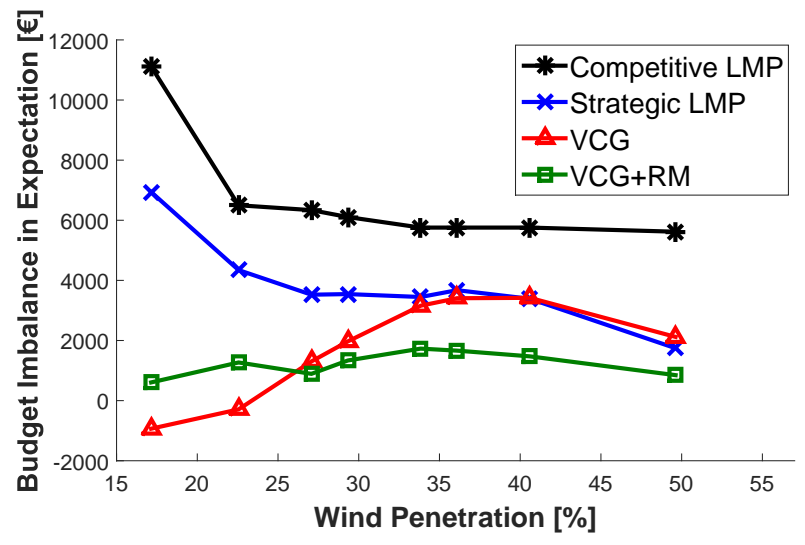

Figure 9. Budget imbalance in expectation before and after the proposed redistribution of budget imbalance versus increasing levels of wind power penetration.

\section{Ex-post Budget Imbalance Redistribution Under the VCG Mechanism}

In this subsection we apply the proposed redistribution scheme of subsection II-D to the presented case study. Fig. 9 presents the results of the corrected budget imbalance following the redistribution mechanism (denoted by $V C G+R M$ ) and compares it with Competitive $L M P$ and $V C G$ market results before redistribution. Regarding the resulting budget imbalance we observe that the negative budget imbalance for low wind power penetration levels is fully recovered after redistribution, and becomes positive. Furthermore, rewarding market agents that contribute towards revenue-adequacy leads to decreased budget imbalance for the case where revenueadequacy was met prior redistribution. The resulted positive budget imbalance of the proposed redistribution mechanism should only be considered as a better approximation of budget balance and is not associated with grid owner payments.

Fig. 10 presents the profits of selected conventional producers after budget redistribution. It is observed that producer G2 is mostly affected by the redistribution scheme and its profit decreases to levels lower than the corresponding under Competitive LMP mechanism for the lowest wind power penetration scenario. However, producer G2 has increased profits for all other scenarios of wind power penetration. Generally, most producers still benefit from $V C G$ model after redistribution compared to Competitive LMP. On the other hand, wind producers participate the least to the redistribution scheme and, thus, their profits do not change considerably. Generally, wind producers still benefit of a marginal increase in their profits after redistribution for high levels of wind power penetration.

Finally, demands' payments after redistribution are presented in Fig. 11 for selected consumers. It was observed that some demands, e.g., consumer D16, have slightly increased payments after redistribution for low wind penetration levels but the opposite for higher penetration levels. In general all demands are still exposed to higher payments under Competitive LMP market, even after the additional redistribution payments.
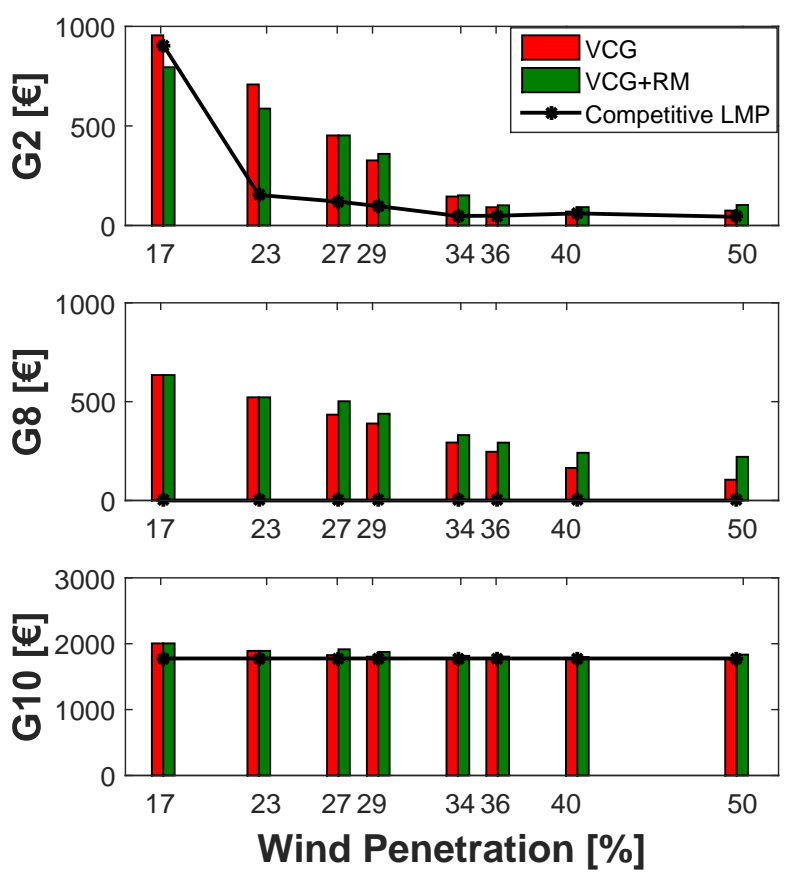

Figure 10. Expected profit of selected conventional producers before and after implementing the proposed redistribution of budget imbalance versus
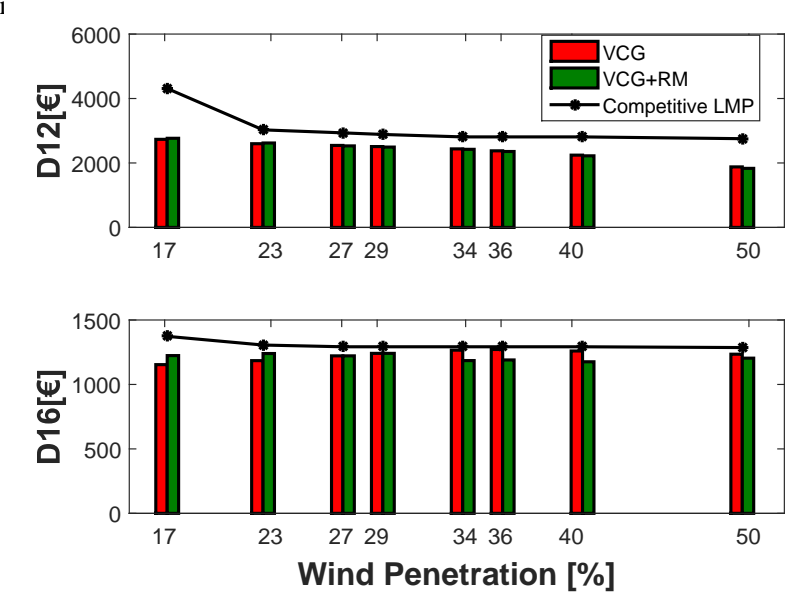

Figure 11. Expected payment of selected demands before and after implementing the proposed redistribution of budget imbalance versus increasing levels of wind power penetration

\section{Practical Implementation and Computational Complexity}

As already explained, both LMP and VCG mechanisms use the same optimization tool for clearing the market and their only difference is the way they price electricity. Therefore, the data and information availability for the practical implementation of VCG mechanism would essentially be the same with the traditional LMP-based market mechanism.

Under VCG, there is no uniform price and this mechanism may end up in different prices for different agents. However, the volatility of these individual prices might be considerably high, and thus, may lead to unpredictable prices and profitability for the market participants. By definition though, market participants are not able to exercise market power and are 
incentivized to offer their true preferences, irrespective of the expected market price. At the same time, cost recovery is also guaranteed under such a scheme and power producers will not face any loss from participating in the market.

Regarding the computational burden in VCG mechanism, based on its definition, the market-clearing optimization problem needs to be solved several times, i.e., equal to the number of the participating agents (each time, the corresponding agent is out of the market) plus one (the case under which all agents exist in the market). However, all these optimization problems can be solved in parallel, since they are all independent. Therefore, compared to the LMP mechanism, the VCG one does not bring considerable computational complexity. The same explanation is valid for the proposed ex-post redistribution mechanism, since it is solved for each agent independently and in parallel. In the following section we provide a larger case study which aims to explore the scalability of VCG mechanism under a power system with more market players and an increased number of wind power scenarios.

\section{CAse study: IEEE 118-Bus Test System}

The case study is based on the IEEE 118-bus test system [36] and, in contrast to Section III, the solution of the "Strategic LMP" model is ignored since it is not relevant in evaluating scalability of neither of the two mechanisms. In this case study, the considered total load is $3,733 \mathrm{MW}$, consisting of 91 demands (namely, D1-D91) with properties as listed in [36], while demand bids are elastic and the value of lost load is $€ 200 / \mathrm{MWh}$. From the generation side, 19 conventional power units (namely, G1-G19) are considered, with total installed capacity of 4,377 MW. Each conventional unit offers at a quantity identical to its installed capacity and at a given price. In addition to conventional units, we consider 17 wind power units located in different buses, as proposed in [36]. Wind power scenarios are sampled from a beta distribution with shape parameters $(\alpha, \beta)=(5,1)$. An initial number of 2,000 wind power scenarios are generated and then reduced to 50, similarly to Section III. This is a considerably greater number of scenarios compared to the case study of Section III, aiming to evaluate computational efficiency of the explored mechanism. Lastly, the case study is built on a system with wind power penetration of $22 \%$.

In this case study we compare the results of the VCG model, before and after the redistribution, with the corresponding results of the Competitive LMP. The expected profits of selected conventional producers are presented in Fig. 12. Similarly to the previous section it is observed that profits are generally higher for conventional producers under the $V C G$ mechanism, with the difference ranging from marginal (e.g., producer G4) to considerably high (e.g., producer G1). Regarding the results of the redistribution mechanism, expected profits for conventional producers are marginally lower than $V C G$ and still higher than the Competitive LMP.

In Fig. 13, the expected profits of selected wind producers are presented for the two models. It is observed that in this case study and under the considered wind penetration level, changes in the expected profits of wind power producers are not

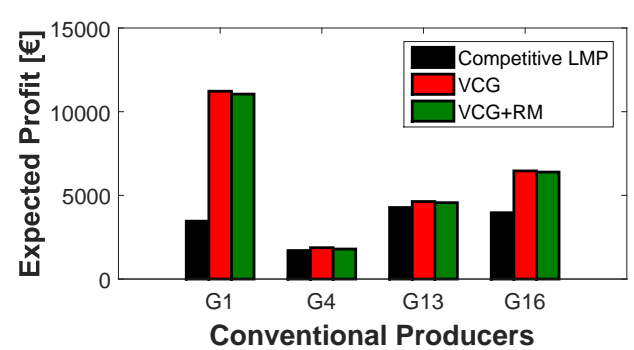

Figure 12. Expected profits of selected conventional producers for both LMP and VCG (before and after redistribution), based on the IEEE 118-bus test system

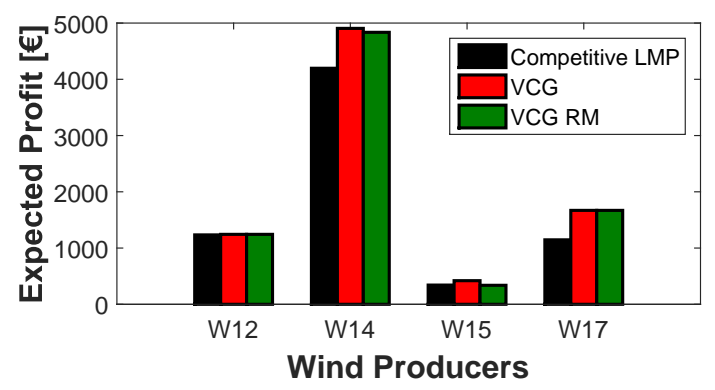

Figure 13. Expected profits of selected wind producers for both LMP and VCG (before and after redistribution), based on the IEEE 118-bus test system

significant. However, depending on the location of the wind producer, there can be an increase in profits under the $V C G$ model as observed in the case of producers W12 and W14. Similarly to the results for the conventional producers, the expost redistribution mechanism is not leading to considerable changes on the profits of wind power producers, since the redistribution charges are distributed among a higher number of market players.

Lastly, in Fig. 14 we present the expected payments of selected demands. The results lead to the same conclusions as the previous section, with decreased demand payments under the VCG model, but not always considerable. It is also observed that demand payments do not considerably change after redistribution for this case study. This result partly explains the fact that negative budget imbalance, even though it is reduced after redistribution, still remains high, as presented in Table II. Social welfare is identical through all the three cases since the generation dispatch is identical.

Concerning computational efficiency, for this case study, we have used solver CPLEX under GAMS, associated with Matlab R2015b on a Windows 10, 64 bit operating system with 2 cores processor running at $2.4 \mathrm{GHz}$ and $12 \mathrm{~GB}$ of RAM. Computational times for the LMP model range between 8-10 seconds, while for VCG, either before or after redistribution, computational times remain 5-10 seconds per each of 128 optimization models, which can be solved in parallel (127 market-clearing models excluding one agent each time plus a market-clearing model considering all agents). 


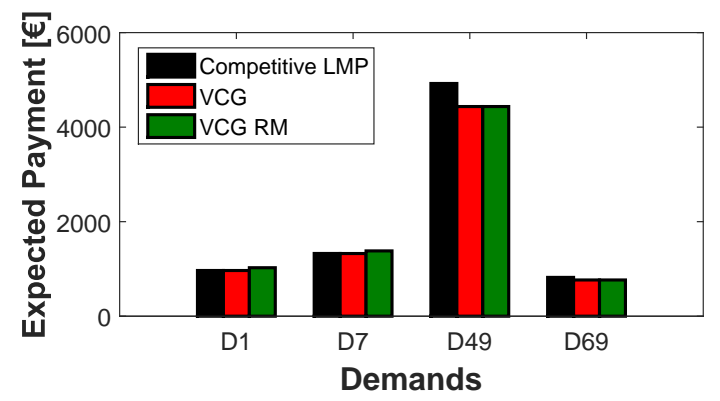

Figure 14. Expected payments of selected demands for both LMP and VCG (before and after redistribution), based on the IEEE 118-bus test system

TABLE II

MARKET RESUltS BASED ON THE IEEE 118-BUS TEST SYSTEM

\begin{tabular}{lll} 
& $\begin{array}{l}\text { Budget Imbalance } \\
\text { (in exp.) }[€]\end{array}$ & $\begin{array}{l}\text { Social Welfare } \\
\text { (in exp.) [€] }\end{array}$ \\
\hline Competitive LMP & 3,093 & 343,550 \\
VCG & $-11,009$ & 343,550 \\
VCG+RM & $-8,584$ & 343,550 \\
\hline
\end{tabular}

\section{Conclusions and Future Perspectives}

\section{A. Conclusions}

Driven by the importance of efficiency in electricity markets, this work explores a VCG auction adaptation on a two-stage stochastic market. The stochastic two-stage model ensures maximum efficiency under high wind penetration, while VCG contributes towards a transparent and incentivecompatible payment scheme. Then the proposed mechanism is compared against traditional LMP setup, under both perfect and imperfect competition. A case study is presented, which numerically concludes in the following points:

1) The VCG mechanism achieves through incentivecompatibility maximum social welfare, equal to the ideal LMP model. On the other hand, imperfect competition may lead to decreased social welfare due to the presence of strategic behaviors.

2) Both conventional and wind producers' profits are higher in VCG mechanism compared to the LMP, but might be even higher under the LMP setup considering imperfect competition. Conventional producers' expected profits generally decrease for both mechanisms as wind power penetration increases.

3) Demands' payments are lower under VCG mechanism, a condition which confirms that consumers are benefiting from an incentive-compatible mechanism. Higher demand payments are observed under the LMP setup considering the presence of strategic producers.

4) Budget imbalance in the market is positive under the LMP mechanism, being the result of the so-called congestion rent. On the other hand, VCG mechanism may lead to negative budget imbalance for low levels of wind penetration, which becomes positive as wind power penetration increases.

Negative budget imbalance is the main shortcoming of VCG mechanism, necessitating an ex-post solution for budget recovery. To this end, a novel budget redistribution mechanism is proposed which aims at partially recovering market budget imbalance by imposing additional payments to market participants. The proposed approach rewards agents that contribute towards revenue-adequacy and charges the ones having negative impact. The proposed redistribution mechanism succeeds to partially recover revenue-adequacy in the market while making it practically difficult for agents to violate the rest of the market properties. Finally, producers and consumers are still benefited compared to the LMP market, for high levels of wind power penetration.

\section{B. Future Perspectives}

The proposed ex-post redistribution mechanism has been applied on the expected budget imbalance of the market. However, it is worth mentioning that it can be used in a similar way to charge/pay the market agents not in expectation but per each individual scenario. This means that the contribution of each agent to create a budget imbalance under each scenario can be calculated, and then a similar mechanism can be used to pay/charge them. However, we anticipate that this revised mechanism may end up in a less efficient redistribution mechanism compared to the one in which the agents' contribution to budget imbalance is calculated in expectation, which however requires further investigation.

Congestion rent payments (and financial transmission rights) are not explored in this paper and exceed its scope. However, it is essential to find a rigorous solution to calculate the economic value of transmission grid under the VCG mechanism. This value needs to be properly defined, which will eventually build a basis for the market operator's payment to the grid owner or the financial transmission right holders.

An additional concern regarding the VCG mechanism is whether existing (or even prospective) producers are able to anticipate the economic viability of their assets, given the volatility and unpredictability of prices under such a payment scheme. Such an uncertainty might have significant impacts on the evolution of the market, which are not straightforward to predict and would need additional investigations, which are left for future research.

Lastly, future research on VCG application in electricity markets should explore how the risk aversion of producers may impact market payments under the VCG mechanism, as in [37], [38] for LMP markets, and investigate the possibility of risk trading among market agents [39].

\section{ACKNOWLEDGMENTS}

The authors would like to thank Orçun Karaca and Maryam Kamgarpour (ETH Zurich) for their helpful comments and discussions.

\section{REFERENCES}

[1] D. Kirschen and G. Strbac, Fundamentals of Power System Economics. Wiley, 2004.

[2] S. Borenstein, J. B. Bushnell, and F. A. Wolak, "Measuring Market Inefficiencies in California's Restructured Wholesale Electricity Market,' The American Economic Review, vol. 92, no. 5, pp. 1376-1405, 2002.

[3] F. A. Wolak, "Measuring Unilateral Market Power in Wholesale Electricity Markets: The California Market, 1998-2000," The American Economic Review, vol. 93, no. 2, pp. 425-430, 2003. 
[4] D. P. Brown and D. E. H. Olmstead, "Measuring market power and the efficiency of Alberta's restructured electricity market: An energy-only market design," Canadian Journal of Economics / Revue canadienne d'économique, vol. 50, no. 3, pp. 838-870, Aug. 2017.

[5] A. Hortaçsu and S. L. Puller, "Understanding strategic bidding in multiunit auctions: a case study of the Texas electricity spot market," RAND Journal of Economics, vol. 39, no. 1, pp. 86-114, 2008.

[6] V. Moutinho, A. C. Moreira, and J. Mota, "Do regulatory mechanisms promote competition and mitigate market power? Evidence from Spanish electricity market," Energy Policy, vol. 68, pp. 403 - 412, 2014.

[7] S. Borenstein and J. Bushnell, "The U.S. Electricity Industry After 20 Years of Restructuring," Tech. Rep., April 2015.

[8] Y. Lee, J. Hur, R. Baldick, and S. Pineda, "New Indices of Market Power in Transmission-Constrained Electricity Markets," IEEE Trans. Power Syst., vol. 26, no. 2, pp. 681-689, May 2011.

[9] W. Vickrey, "Counterspeculation, auctions, and competitive sealed tenders," The Journal of Finance, vol. 16, no. 1, pp. 8-37, 1961.

[10] E. H. Clarke, "Multipart pricing of public goods," Public Choice, vol. 11, no. 1, pp. 17-33, Sep 1971

[11] T. Groves, "Incentives in teams," Econometrica, vol. 41, no. 4, pp. 617631, 1973

[12] J. M. Morales, A. J. Conejo, K. Liu, and J. Zhong, "Pricing electricity in pools with wind producers," IEEE Trans. Power Syst., vol. 27, no. 3, pp. 1366-1376, Aug. 2012

[13] G. Pritchard, G. Zakeri, and A. Philpott, "A single-settlement, energyonly electric power market for unpredictable and intermittent participants," Oper. Res., vol. 58, no. 4-part-2, pp. 1210-1219, Apr. 2010.

[14] J. Kazempour, P. Pinson, and B. F. Hobbs, "A stochastic market design with revenue adequacy and cost recovery by scenario: Benefits and costs," IEEE Trans. Power Syst., vol. 33, no. 4, pp. 3531-3545, Jul 2018.

[15] V. M. Zavala, K. Kim, M. Anitescu, and J. Birge, "A stochastic electricity market clearing formulation with consistent pricing properties," Oper. Res., vol. 65, no. 3, pp. 557-576, 2017.

[16] J. R. Green and J. J. Laffont, Incentives in Public Decision-Making. North Holland, New York, 1979.

[17] B. F. Hobbs, M. H. Rothkopf, L. C. Hyde, and R. P. O’Neill, "Evaluation of a truthful revelation auction in the context of energy markets with nonconcave benefits," J. Reg. Econ., vol. 18, no. 1, pp. 5-32, 2000.

[18] Y. Xu and S. H. Low, "An efficient and incentive compatible mechanism for wholesale electricity markets," IEEE Trans. Smart Grid, vol. 8, no. 1, pp. 128-138, Jan. 2017.

[19] D. J. Roberts and A. Postlewaite, "The incentives for price-taking behavior in large exchange economies," Econometrica, vol. 44, no. 1, pp. $115-127,1976$.

[20] R. P. O’Neill, P. M. Sotkiewicz, B. F. Hobbs, M. H. Rothkopf, and W. R. Stewart, "Efficient market-clearing prices in markets with nonconvexities," European Journal of Operational Research, vol. 164, no. 1, pp. $269-285,2005$.

[21] R. Myerson and M. A. Satterthwaite, "Efficient mechanisms for bilateral trading," Journal of Economic Theory, vol. 28, pp. 265-281, 1983.

[22] R. Cavallo, "Optimal decision-making with minimal waste: Strategyproof redistribution of VCG payments," in 5th International Joint Conference on Autonomous Agents and Multiagent Systems (AAMAS 2006), Hakodate, Japan, May 2006.

[23] C. Silva, B. F. Wollenberg, and C. Z. Zheng, "Application of mechanism design to electric power markets," IEEE Trans. Power Syst., vol. 16, no. 4, pp. 862-869, Nov. 2001

[24] P. Zou, Q. Chen, Q. Xia, C. He, and C. Kang, "Incentive compatible pool-based electricity market design and implementation: A Bayesian mechanism design approach," Appl. Energy, vol. 158, pp. 508-518, 2015.

[25] B. F. Hobbs, C. B. Metzler, and J. S. Pang, "Strategic gaming analysis for electric power systems: an MPEC approach," IEEE Trans. Power Syst., vol. 15, no. 2, pp. 638-645, May 2000.

[26] L. Exizidis, "Electricity Markets with High Wind Power Penetration: Information Sharing and Incentive- Compatibility," Ph.D. dissertation, Dec. 2017. [Online]. Available: https://doi.org/10.5281/zenodo.1195538

[27] J. B. Cardell, C. C. Hitt, and W. W. Hogan, "Market power and strategic interaction in electricity networks," Resource and Energy Economics, vol. 19, no. 1-2, pp. 109-137, 1997.

[28] B. E. Hobbs, "Linear complementarity models of Nash-Cournot competition in bilateral and poolco power markets," IEEE Trans. Power Syst., vol. 16, no. 2, pp. 194-202, May 2001.

[29] S. J. Kazempour, A. J. Conejo, and C. Ruiz, "Strategic generation investment using a complementarity approach," IEEE Trans. Power Syst. vol. 26, no. 2, pp. 940-948, Apr. 2011.
[30] T. Dai and W. Qiao, "Finding equilibria in the pool-based electricity market with strategic wind power producers and network constraints," IEEE Trans. Power Syst., vol. 32, no. 1, pp. 389-399, Jan. 2017.

[31] L. Exizidis, J. Kazempour, P. Pinson, Z. D. Grève, and F. Vallée, "Impact of public aggregate wind forecasts on electricity market outcomes," IEEE Trans. Sustain. Energy, vol. 8, no. 4, pp. 1394-1405, Oct. 2017.

[32] Reliability Test System Task Force, "The IEEE reliability test system1996," IEEE Trans. Power Syst., vol. 14, no. 3, pp. 1010-1020, Nov./Dec. 1999

[33] C. Ordoudis, P. Pinson, J. M. Morales, and M. Zugno, An Updated Version of the IEEE RTS 24-Bus System for Electricity Market and Power System Operation Studies. Technical University of Denmark, 2016.

[34] H. Bludszuweit, J. A. Dominguez-Navarro, and A. Llombart, "Statistical analysis of wind power forecast error," IEEE Trans. Power Syst., vol. 23, no. 3, pp. 983-991, Aug. 2008

[35] A. Likas, N. Vlassis, and J. J. Verbeek, "The global K-Means clustering algorithm," Pattern Recognition, vol. 36, no. 2, pp. 451-461, Feb. 2003.

[36] I. Peña, C. B. Martinez-Anido, and B. Hodge, "An Extended IEEE 118Bus Test System With High Renewable Penetration,” IEEE Trans. Power Syst., vol. 33, no. 1, pp. 281-289, Jan. 2018.

[37] Y. Zhang and G. B. Giannakis, "Distributed stochastic market clearing with high-penetration wind power," IEEE Trans. Power Syst., vol. 31, no. 2, pp. 895-906, Mar. 2016.

[38] J. Kazempour and P. Pinson, "Effects of risk aversion on market outcomes: A stochastic two-stage equilibrium model," in $16^{\text {th }}$ International Conference on Probabilistic Methods Applied to Power Systems (PMAPS), Beijing, China, Oct. 2016

[39] H. Gérard, V. Leclère, and A. Philpott, "On risk averse competitive equilibrium," Operations Research Letters, vol. 46, no. 1, pp. $19-26$, 2018.

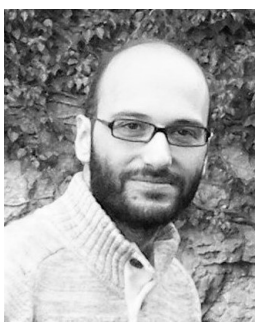

Lazaros Exizidis (M'18) received his diploma in Electrical and Computer Engineering from the Aristotle University of Thessaloniki (AUTH) and his $\mathrm{Ph} . \mathrm{D}$. from the the University of Mons (UMONS). His research interests include optimization methods in power systems and electricity markets as well as energy economics.

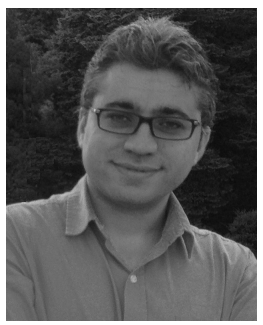

Jalal Kazempour (SM'18) is an assistant professor at the Department of Electrical Engineering, Technical University of Denmark, Kgs. Lyngby, Denmark. $\mathrm{He}$ received his Ph.D. degree in electrical engineering from University of Castilla-La Mancha, Ciudad Real, Spain, in 2013. His research interests include power systems, electricity markets, optimization, and its applications to energy systems. 


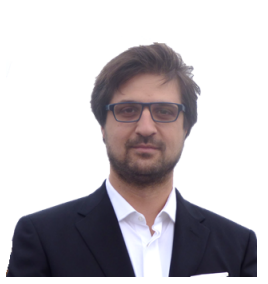

Athanasios Papakonstantinou graduated from the Dept. of Mathematics of the Aristotle University of Thessaloniki, Greece at 2005 and completed his postgraduate studies in Applied Mathematics and Game Theory (MSc in Mathematics with Modern Applications, Mathematics Dept, The University of York, UK) at 2006. He got a $\mathrm{PhD}$ in Computer Science at 2010 from the School of Electronics and Computer Science in the University of Southampton in the UK. Since then he has been employed as a post-doctoral researcher in Copenhagen Business School (CBS) and the Technical University of Denmark (DTU). Today he is a tenure track research scientist in the Dept. of Management Engineering in DTU. His research lies in the intersection of Economics, Optimisation and Power Systems with applications in energy related topics (i.e. electricity market design and trading strategies, demand response and smart grid technologies).

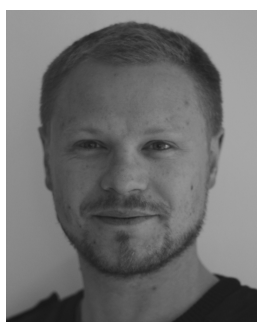

Pierre Pinson (M'11-SM'13) received the M.Sc. degree in applied mathematics from the National Institute for Applied Sciences (INSA Toulouse, France) and the Ph.D. degree in energetics from Ecole des Mines de Paris (France). He is a Professor at the Technical University of Denmark (DTU), Centre for Electric Power and Energy, Department of Electrical Engineering, also heading a group focusing on Energy Analytics \& Markets. His research interests include among others forecasting, uncertainty estimation, optimization under uncertainty, decision sciences, and renewable energies. Prof. Pinson acts as an Editor for the International Journal of Forecasting, and for Wind Energy.

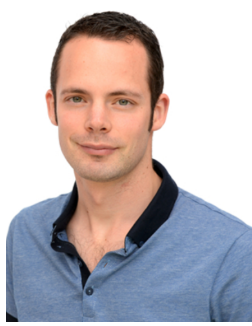

Zacharie De Grève (M'12) holds an Electrical and Electronics Engineering degree from the Faculty of Engineering of Mons, Belgium (2007). He has been a research fellow of the Belgian Fund for Research (F.R.S/FNRS) until 2012, when he got the $\mathrm{PhD}$ degree in Electrical Engineering, from the University of Mons. He is now a research and teaching assistant at the Power Electrical Department of the same university. His research interests focus on the one hand on the integration of renewable energy sources in electrical power systems, with a specific emphasis on data analytics, and on computational electromagnetics on the other hand (finite element method, integral methods, etc.).

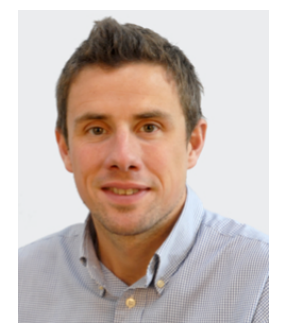

François Vallée (M'09) received his degree in civil electrical engineering and the Ph.D. degree in electrical engineering from Faculté Polytechnique de Mons (Belgium) in 2003 and 2009, respectively. He is currently an Associate Professor in the Power Electrical Engineering Unit of Faculté Polytechnique, University of Mons (Belgium). His fields of interest mainly include wind generation modelling and electrical network reliability in presence of dispersed generation. 